$\begin{array}{ll} & \text { Etnográfica } \\ \text { etnográfica } & \text { Revista do Centro em Rede de Investigação em }\end{array}$ Antropologia

vol. 24 (1) | 2020

Vol. $24(1)$

\title{
Indefensión, injusticia y merecimiento en el colectivo de trabajadoras del hogar: análisis de casos judicializados
}

Defenselessness, injustice and deservingness regarding domestic workers:

analysis of two judicial cases

\section{Sílvia Bofill-Poch y Raúl Márquez Porras}

\section{(2) OpenEdition}

\section{Journals}

\section{Edición electrónica}

URL: https://journals.openedition.org/etnografica/8487

DOI: 10.4000/etnografica.8487

ISSN: 2182-2891

\section{Editor}

Centro em Rede de Investigação em Antropologia

Edición impresa

Fecha de publicación: 1 febrero 2020

Paginación: 225-244

ISSN: 0873-6561

\section{Referencia electrónica}

Sílvia Bofill-Poch y Raúl Márquez Porras, «Indefensión, injusticia y merecimiento en el colectivo de trabajadoras del hogar: análisis de casos judicializados», Etnográfica [En línea], vol. 24 (1) | 2020, Publicado el 25 febrero 2020, consultado el 20 enero 2022. URL: http://journals.openedition.org/ etnografica/8487 ; DOI: https://doi.org/10.4000/etnografica.8487

\section{(c) (7) \&}

Etnográfica is licensed under a Creative Commons Attribution-NonCommercial 4.0 International License. 


\section{Indefensión, injusticia}

\section{y merecimiento en el colectivo de trabajadoras del hogar: análisis de casos judicializados}

\section{Sílvia Bofill-Poch y Raúl Márquez Porras}

Las trabajadoras del hogar en España ocupan una posición vulnerable en el mercado laboral, y en general en la sociedad, causada por un complejo entramado de factores económicos, legales y culturales. Esta vulnerabilidad se traduce en una exposición elevada a acusaciones de tipo penal, principalmente por hurto, robo o estafa, las cuales esconden, en realidad, motivaciones laborales. Estas acusaciones desvelan la indefensión que sufren las trabajadoras en el ámbito de la justicia estatal, así como significados y dinámicas de fondo en su relación con empleadores/as, operadores jurídicos y agentes del Estado. Abordamos aquí dos casos judicializados, reconstruidos a partir de testimonios directos. Mostrando las imbricaciones de las dimensiones legales y morales del derecho, destacamos: la banalización de las acusaciones penales por los/as empleadores/as; la interpretación en términos de merecimiento por todas las partes; el ensañamiento con que actúan los/as empleadores/as y sus representantes; y los factores objetivos de riesgo que sufren las trabajadoras al desempeñar su labor en domicilios particulares. También analizamos los estigmas y prejuicios de género, clase y raza que otorgan credibilidad a las demandas y determinan, en gran medida, los procesos judiciales. Contrariamente a lo que podríamos esperar, el derecho se convierte en un instrumento de agresión para sostener injusticias, indefensiones y vulnerabilidades.

PALABRAS CLAVE: trabajo del hogar, robo, demandas judiciales, moralidad, injusticia, merecimiento.

Defenselessness, injustice and deservingness regarding domestic workers: analysis of two judicial cases - Domestic workers in Spain occupy a vulnerable position in the labor market, and in society in general, due to economic, legal and cultural factors. Because of this vulnerability, they are frequently accused of crimes by their employers, in particular theft, robbery or fraud. These accusations, in fact, hide work-related motives and reveal the defenselessness of the workers in the face of the justice system, as well as unequal dynamics in their relationships with employers, legal and state agents. We address two judicial cases reconstructed from direct testimonies. Showing overlaps in the legal and moral dimensions of law, we highlight the banalization of criminal accusations by employers; the use of the frame of deservingness by all parties; the cruelty in the action of employers and their representatives; and the objective risks that the workers are submitted to when performing their work in private homes. We also address the stigmas and prejudices related to gender, class and race that give credibility to the lawsuits and determine, to a large extent, their outcomes. Contrary to what we might expect, 
the law becomes an instrument of aggression to sustain injustice, defenselessness and vulnerability.

KEYWORDS: domestic work, lawsuit, theft, morality, injustice, deservingness.

BOFILL-POCH, Sílvia (bofill@ub.edu) - Departamento de Antropología Social, Universitat de Barcelona, España.

MÁRQUEZ PORRAS, Raúl (raulmarquez@ub.edu) - Departamento de Antropología Social, Universitat de Barcelona, España.

\section{INTRODUCCIÓN}

El sector del trabajo del hogar y los cuidados en España, ocupado en gran medida por mujeres inmigrantes, se caracteriza por una gran desregulación, por condiciones de trabajo muy precarias (posibilidad de desistimiento, falta de estabilidad y de garantías laborales, elevada informalidad...) y, más aún, por situar a las trabajadoras en una posición de extrema vulnerabilidad. ${ }^{1}$ Por vulnerabilidad entendemos la mayor posibilidad de verse expuestas a riesgos y sufrir daños, y tener menos capacidades para proteger los propios intereses (Mackenzie 2014). ${ }^{2}$ A pesar de los avances legislativos más o menos recientes, sigue siendo un sector laboral deficitario en materia de reconocimiento de derechos. ${ }^{3}$ Los colectivos de trabajadoras han denunciado el carácter insuficiente de dichas reformas, por cuanto omiten, sino refuerzan, elementos estructurales causantes de desigualdad e indefensión. ${ }^{4}$

Lo destacable es que la posición vulnerable y la relativa indefensión de las trabajadoras del hogar tienen que ver con factores sociales, económicos y culturales, con el contexto en el cual desarrollan su tarea, con la propia

I Esta investigación forma parte de una investigación mayor sobre el acceso a la justicia de las mujeres inmigrantes trabajadoras del hogar en España. Parte de los resultados han sido elaborados dentro del proyecto "Concepciones Populares de la Justicia Social ante la Crisis y las Políticas de Austeridad" (CSO2015-67368-P), coordinado por Mikel Aramburu y Sílvia Bofill-Poch y financiado por el Ministerio de Economía y Competitividad español y el Fondo Europeo de Desarrollo Regional (Feder), en el periodo 2016-2018.

2 Véase Martínez-Buján (2011), Nogueira y Zalakain (2015), Bofill-Poch (2017), Offenhenden (2017).

3 Ley 27/201 1, sobre actualización, adecuación y modernización del sistema de Seguridad Social (BOE n. ${ }^{\circ}$ 184); Real Decreto 1620/2011, por el que se regula la relación laboral de carácter especial del servicio del hogar familiar (BOE n. ${ }^{\circ}$ 277); Real Decreto-Ley 29/2012, de 28 de diciembre, de mejora de gestión y protección social en el Sistema Especial para Empleados de Hogar (BOE n. ${ }^{o} 314$ ).

4 La nueva normativa inscribe por primera vez a las trabajadoras en el Régimen General de la Seguridad Social, pero lo hace en un régimen específico de cotización, el cual no reconoce, por ejemplo, el derecho a una prestación por desempleo ni permite aplicar la normativa de riesgos laborales. Véase el documento "Propostes per a la dignificació del treball de la llar i la cura de les persones" (CMIB 2017). 
conceptualización del trabajo del hogar y los cuidados - históricamente minusvalorado -, así como con la discriminación de género y fenómenos de xenofobia. En definitiva, cabe relacionarlo con la condición de mujeres, con el estatus de migrante y de clase baja, y con los prejuicios, estereotipos y actitudes que ello genera en los/as empleadores/as y demás actores. Es la confluencia de todas estas variables la que sitúa a las trabajadoras del hogar y los cuidados en una posición vulnerable, posición que es estructural y persistente y que se traduce, entre otras cosas, en una desigualdad manifiesta en el acceso a la Justicia y la negociación laboral. De manera concreta, por las condiciones en que desempeñan su trabajo (en un domicilio privado, bajo un empleador/a particular, etc.) y por la posición minusvalorada que ocupan, estas trabajadoras no sólo carecen de la potestad para negociar los términos de la relación laboral y hacer que se respeten los derechos que la legislación les concede, sino que son punidas, en ocasiones, por el hecho mismo de reclamar: reciben acusaciones y/o amenazas de índole penal por parte de los/as empleadores/as, en el marco de un conflicto que es de raíz laboral pero que saca a relucir los estereotipos, la indefensión y la vulnerabilidad sufridas por las trabajadoras del hogar y los cuidados. En términos de merecimiento, las trabajadoras actúan creyendo merecer determinado reconocimiento de derechos y gratificaciones, mientras que los/as empleadores/as leen el reclamo de quien en realidad está siendo "ayudada" como una afrenta que merece un correctivo. Un correctivo de tal magnitud que se realiza en el ámbito de la justicia oficial y mediante una acusación penal.

Queremos ilustrar todo ello mediante dos casos recientes, ambos relacionados con la acusación de hurto agravado y de estafa hacia trabajadoras. Por la gravedad de los delitos imputados, ambos juicios se celebraron en la Audiencia Provincial de Barcelona (tribunal de segunda instancia). Estos dos casos, aunque algo distintos - en uno el conflicto laboral pasa casi desapercibido; en el otro la disputa laboral es manifiesta, así como el uso estratégico de la imputación penal -, evidencian la comentada exposición al riesgo y la indefensión de las trabajadoras, así como los prejuicios de género, estatus y clase de muchos empleadores/as y operadores de la Justicia. Es destacada en ambos la actuación desmesurada de alguno de ellos, lo que definimos como "ensañamiento".

Nuestra investigación se inscribe en la línea de trabajos sociológicos y antropológicos recientes sobre litigios judiciales que analizan la tensión y/o articulación entre las dimensiones legales y morales del derecho (véase Terradas et al. 2016; Pérez y Canevaro 2016; Canevaro 2015; Eilbaum 2011; Oliveira 2004; Macaya 2013; Canyelles 2019), trabajos que han subrayado los supuestos morales que subyacen en narrativas y procesos judiciales o, en palabras de Terradas et al. (2016: 10), los trasfondos socio-culturales que influyen en la praxis judicial.

Los objetivos del artículo son dos. En primer lugar, se trata de resaltar el modo en que los componentes extra-legales (prejuicios, estereotipos y 
elementos que restan valor y capacidad de defensa) entran dentro del procedimiento judicial. Aquí, la cuestión del merecimiento aparece como argumento moral con múltiples sentidos. Por parte de los/as empleadores/as, sustenta el castigo hacia quien se atreve a desafiar la jerarquía y el orden de subordinación. Por parte de las trabajadoras, sustenta la demanda de una gratificación justa por el trabajo desarrollado, así como la expresión de injusticia hacia un ataque que se considera, además de infundado, desproporcionado. En segundo lugar, y en estrecha articulación con lo anterior, mostramos el uso estratégico del derecho por parte de los/as empleadores/as en aras a reforzar el orden de subordinación dentro del cual se dirime la relación laboral (y los conflictos que de dicha relación emanan). Contrariamente a lo que podría esperarse, a través del derecho dicho orden de estatus - que desafía la legalidad estricta - persiste y se ve reforzado. El derecho se convierte aquí en un instrumento de agresión para sostener injusticias, indefensiones y vulnerabilidades.

\section{APUNTE METODOLÓGICO}

En el marco del proyecto mencionado sobre acceso a la justicia de trabajadoras del hogar de origen inmigrante, se ha trabajado con dos abogadas que han llevado expedientes afectando a trabajadoras (asuntos penales que partían de una relación laboral, como se comentará), ambas letradas con una dilatada experiencia profesional y activista, una perspectiva crítica del derecho y una voluntad de denuncia de las inequidades del sistema de justicia. Con ellas se trabajó durante el 2018 en la reconstrucción y análisis de media docena de casos, en una labor de interpretación conjunta de los documentos derivados de los procedimientos (escritos de la defensa y acusación, sentencias, recursos...) y de las circunstancias extralegales que rodearon cada caso. En este sentido, las abogadas proporcionaron datos contextuales precisos sobre el desarrollo de los litigios, más allá de lo reflejado en los documentos, además de aclarar el sentido de muchos términos jurídicos, en un diálogo fructífero donde las preguntas de la antropóloga y el antropólogo suscitaron también - en palabras de las propias letradas - una nueva perspectiva sobre estos conflictos. Del total de casos reconstruidos conjuntamente, seleccionamos los dos que presentamos en este artículo por su relevancia.

Cabe señalar, por lo demás, algunas similitudes y diferencias en cuanto a fuentes, metodología y estado de los casos al abordar su estudio. El caso de la trabajadora que llamaremos Aurora se trabajó a partir de un expediente que incluía desde la primera denuncia del empleador, hasta la solicitud de indulto por parte de la trabajadora, una vez condenada, y el escrito de oposición del empleador. La abogada de Aurora - profesional autónoma - había cogido el caso después de que ella renunciara a la abogada asignada de oficio, descontenta con su labor, a través de un antiguo cliente y de manera fortuita. En el 
caso de Manuela - nombre igualmente ficticio - tuvo mayor peso el testimonio de la abogada, aunque pudo consultarse también el expediente judicial, y se llegó a entrevistar a la propia trabajadora. En este caso, la abogada toma lo que es inicialmente un asunto laboral para hacerse cargo después de la deriva penal del mismo, que había asumido inicialmente otra compañera del colectivo de defensa de los derechos humanos del cual formaba parte.

Según el testimonio de ambas abogadas, los casos de Aurora y Manuela no resultan únicos ni excepcionales. El hecho es que, consultando en algunas bases jurisprudenciales, más de la mitad de los casos que involucran directamente a "empleadas del hogar" - o sea, a éstas en el desempeño de su labor son del ámbito penal y tienen que ver con acusaciones de hurto, robo o estafa en el domicilio del / de la empleador/a. ${ }^{5}$ Investigaciones como la de Borrell (2015), por lo demás, han mostrado que el uso fraudulento de estas acusaciones por parte de los/as empleadores/as es un fenómeno histórico en la sociedad barcelonesa, relacionado con estereotipos y representaciones peyorativas sobre las trabajadoras que estarían plenamente vigentes en los medios de comunicación de alcance estatal, en los que la mayor parte de noticias que versan sobre trabajadoras del hogar y los cuidados hablan de acusaciones de hurto, robo o estafa (Almena Cooperativa Feminista 2019).

\section{LA ACUSACIÓN DE ROBO COMO RECURSO RUTINARIO DE NEGOCIACIÓN LABORAL}

Las acusaciones de hurto o estafa (delito más grave y que comporta penas más elevadas) no suelen llegar a juicio. Esto se relaciona con ciertos factores materiales. Querellarse a nivel penal presupone tiempo y dinero, además de un conocimiento del mundo judicial que no es habitual ni asequible para la mayoría de las personas que contratan trabajadoras del hogar.

No obstante, dichas acusaciones sí serían un instrumento habitual usado por los/as empleadores/as en las negociaciones con las trabajadoras; se observa, por ejemplo, en los casos de despido improcedente, motivo por el que suelen iniciarse la mayoría de litigios contra empleadores/as. Con el objeto de ahorrarse parte de la indemnización, ${ }^{6} \mathrm{el} / \mathrm{la}$ empleador/a - generalmente aconsejado/a por

5 Concretamente, una búsqueda en la base jurisprudencial Vlex, ceñida a los años 2012-2018 y a la provincia de Barcelona, arroja como resultado que más del $60 \%$ de los autos y sentencias conteniendo la voz "empleada del hogar" se refieren a casos de hurto, robo o estafa en que la empleada es la parte acusada. Cabe decir que la representatividad del registro jurisprudencial es limitada: los conflictos laborales por despido, en que se reclama una indemnización o los salarios impagados, suelen acabar en un pacto informal y por lo tanto no dejan registro oficial; lo mismo ocurre con los casos de agresión sexual, que pese a ser muy frecuentes raramente se denuncian (Bofill-Poch y Véliz 2019).

6 Sobre un sueldo promedio de 700 euros y a tenor de 20 días por año trabajado, corresponderían de indemnización 466 euros por año trabajado. 
su abogado - arguye que la trabajadora le habría robado (lo cual justificaría un despido procedente) y la denuncia. Con esto, desplaza el conflicto del ámbito laboral al penal. En base a un imaginario cultural ampliamente extendido que representa a las trabajadoras del hogar extranjeras como "mujeres propensas al robo" - como pretendemos ilustrar en los casos que presentamos -, estas acusaciones encuentran recorrido.

La acción sirve para chantajear a la trabajadora y afianzar una posición de superioridad en la negociación laboral, para acallar posibles resistencias, e incluso denuncias por abuso o acoso sexual (Bofill-Poch y Véliz 2019). Esta instrumentalización del derecho, y la banalización de la figura penal de hurto o estafa, resultaría una expresión clara de la desigualdad de facto entre los actores, de la indefensión y vulnerabilidad que sufren las trabajadoras. Un ingrediente que puede resultar también sorprendente, como el "ensañamiento" o desmesura en el ataque por parte de los/as empleadores/as, sería igualmente representativo del infra-reconocimiento rutinario y la posición subordinada de las trabajadoras del hogar. Éste sería también una expresión de la naturalización de la violencia que se ejerce cotidianamente sobre estas mujeres. ${ }^{7}$

Presentamos a continuación dos casos paradigmáticos. En ellos se observa, además, cómo la ambigüedad propia del trabajo de hogar, donde se mezclan lo afectivo y lo contractual, impregna las narrativas y estrategias judiciales, y cómo las lógicas afectivas, personales y morales se superponen a aquellas legales, contractuales y meramente jurídicas (Canevaro 2015: 27). La simple acusación de hurto o estafa - hecha de manera fraudulenta - presupone tal superposición, al recurrir a un estereotipo o prejuicio cultural - "mujer extranjera que roba" - como mecanismo de inculpación penal. La eficacia judicial de tal acusación remite a la dimensión pública del prejuicio o estereotipo (Eilbaum 2011), en la medida que conecta con la representación dominante de la trabajadora de hogar extranjera, de quien hay que desconfiar y a quien se le presupone mala fe e intencionalidad delictiva (Offenhenden 2017; Gorban 2012). Este prejuicio, que impregna el conjunto de narrativas judiciales, otorga, por lo demás, plausibilidad y razonabilidad a la estrategia acusatoria.

\section{Caso I: el caso de Aurora}

Aurora nació en 1958 en Argentina, aunque tiene también la nacionalidad italiana. Sin experiencia en el sector del trabajo del hogar, otra vecina de su finca le hace saber que la señora del quinto - de unos 80 años, con Parkinson y postrada en una silla de ruedas - busca cuidadora; así accede al trabajo.

$7 \quad$ Otra expresión clara de esta naturalización, y en este caso por omisión, emerge en el análisis de sentencias de feminicidios recogido en el informe Feminicidio en Euskadi y Navarra (Atencio 2016). Pese al ensañamiento evidente que contienen numerosos casos de asesinato de mujeres (p. ej. asestarle 52 puñaladas), no se hace referencia explícita a él en las sentencias (Atencio 2016: 150). 
Actuará como co-empleador el novio de la señora - el señor J. -, un hombre de poco más de 60 años, conserje de la misma finca. Menos de un año después de empezar a cuidar a la señora M., Aurora se ve envuelta en una acusación grave de robo y hurto: una supuesta sustracción de dinero de las cuentas bancarias de la señora M., y el supuesto robo de unas joyas que se encontraban en el interior de dos cajas fuertes. Será denunciada ante la policía y acabará condenada a más de dos años de cárcel, teniendo que entrar en prisión.

Describiendo cronológicamente y en detalle el caso, Aurora es contratada por el señor J. en noviembre de 2010. Transcurridos diez meses, en septiembre de 2011 , el señor J. interpone una denuncia ante los Mossos d'esquadra (policía autonómica, en adelante Mossos), acusando a Aurora de haber sustraído 24 mil euros de las cuentas bancarias de la señora M. Según explica el señor J. en la denuncia ante la policía, en agosto se dan cuenta de que las libretas del banco estaban manipuladas (páginas arrancadas, importes tachados con corrector...), teniendo "claras sospechas de que había sido Aurora". La habrían llamado para hablar con ella y pedirle que devolviera el dinero, a lo que Aurora habría respondido que no tenía el dinero en aquel momento - reconociendo su culpa, por lo tanto -. Le hacen devolver las llaves del piso y la despiden. Un mes después, en septiembre, se habrían dado cuenta, además, al abrir una de las cajas fuertes del piso, de que la mayor parte de joyas de la señora M. habían desaparecido. Estaban "completamente seguros de que había sido Aurora, porque nadie más tenía acceso a las llaves”. Deciden entonces interponer denuncia ante la policía por "miedo de que Aurora huya a su país".

En el escrito que remiten los Mossos al Juzgado de Instrucción, en octubre, se concluye que la acusación contra Aurora tiene fundamento, dado que Aurora tenía acceso a las libretas y a la caja fuerte; que las sustracciones habían comenzado al ser ella contratada; y que al acompañar regularmente a la señora $\mathrm{M}$. podía haber aprendido el código-pin de las libretas. Acompañan el escrito de imágenes captadas en el cajero de días en que se habrían realizado las sustracciones fraudulentas.

Lo interesante, para nuestro análisis, es que este escrito inicial de los Mossos está lleno de suposiciones y juicios vejatorios contra Aurora, prejuicios que dibujan la imagen de la cuidadora inmigrante que se aprovecha de la empleadora (autóctona) desvalida. Se dice, por ejemplo, que Aurora "pudo aprovecharse durante tanto tiempo [...] sabiendo que son personas de avanzada edad y confiaban en ella". Y se concluye:

"Desde esta unidad se quiere hacer especial inciso en que la pareja denunciante son personas de avanzada edad, y la Sra. Aurora se ha aprovechado de la confianza dada por parte de estas personas actuando con vileza durante más de seis meses, incluso tenía un juego de llaves de su casa para entrar y salir cuando quisiese. La Sra. Aurora ha utilizado el engaño, con intenciones 
de ser la cuidadora y de ayudar a la Sra. M. porque padece una enfermedad crónica y tiene la movilidad reducida, utilizando su invalidez para abusar y sustraerle efectos como dinero de las cuentas bancarias (que podían ser ahorros de personas mayores) y joyas de su propia casa que estaban guardadas desde su propia casa (sin tener en cuenta que podían tener un valor sentimental)" [redacción original].

Aurora es detenida y llevada a declarar ante el juez de guardia. En su declaración manifiesta que desconocía la existencia de una caja fuerte; que utilizó las tarjetas y libretas bancarias “a indicación del señor [el señor J.]”, que ella sacaba el dinero y se lo entregaba a él. Y añade que "todo empezó cuando el señor J. se enteró de que había pedido vacaciones para ir a mi país”, a lo que le respondieron "que no me correspondían, que no tenía contrato". La acusación dirá, en el mismo acto ante el juez, que Aurora se había marchado a Argentina porque sabía que la iban a denunciar. La defensa esgrimirá, entre otras cosas, que resulta inverosímil no darse cuenta de las sustracciones en siete meses; que se había reconocido una relación laboral sin contrato, y que "esta denuncia se interpone únicamente para hacerse valer en una futura denuncia [...] por despido improcedente". Aunque la acusación pide el registro del domicilio de Aurora y su entrada en prisión, el juez sólo decreta la retirada del pasaporte, la prohibición de salida del país y la obligación de comparecer ante él cada quince días.

La acusación hará llegar en las semanas siguientes al menos tres escritos solicitando diligencias de prueba con carácter de urgencia: la toma de huellas dactilares de las cajas fuertes del domicilio de la señora M.; la comprobación de los movimientos en las cuentas de Aurora y de sus familiares; la petición de información a bancos sobre posibles transferencias a Sudamérica, sobre posibles deudas de Aurora y su familia; y un informe de vida laboral para confrontar las manifestaciones de Aurora, que según el abogado de la acusación "intenta hacer valer un problema laboral, para intentar confundir a todo el que pueda alegando todo lo que su imaginación dé de sí" (cita textual). Se apunta de paso que Aurora habría trabajado en algún momento para una empresa de compraventa de oro y joyas, lo que facilitaría el deshacerse de las joyas robadas. El juez desestimará la mayor parte de peticiones, accediendo sólo a la toma de huellas dactilares y a la solicitud de extractos de las cuentas bancarias. La toma de huellas por parte de la policía se realiza a principios de noviembre. En un joyero se encuentran algunas huellas, pero se comprobará que no corresponden a Aurora.

En un escrito, el 2 de diciembre, la defensa solicita que se le devuelva el pasaporte para que Aurora pueda seguir cobrando el subsidio de desempleo y pueda buscar trabajo, ya que su situación económica era precaria y corría riesgo de ser desahuciada. En otro escrito, a finales de diciembre, el abogado de la acusación insiste en el valor de las joyas supuestamente robadas, en que 
"la denunciada se aprovechó del estado de salud de mi patrocinada", y se queja de la dilación del proceso, además de pedir que tomen de nuevo las huellas de las cajas fuertes, insinuando mala praxis del policía encargado. El Juzgado desestima la petición.

A principios de enero la defensa solicita que Aurora pueda volver a declarar, para, entre otras cosas, "aclarar quién, cómo y cuánto se le abonaba en concepto de salario por sus servicios de cuidadora, dado que no fue dada de alta por su empleadora". Se intenta, así, situar el conflicto en el terreno de lo laboral. También se pide que declare el señor J., para que aclare con qué asiduidad retiraba él dinero; también la señora M., para preguntarle por los servicios que le prestaba Aurora, y la cuñada de ésta (viuda de su hermano fallecido). La cuñada hará llegar a la abogada defensora un escrito remitido a la asistenta social del Hospital Clínico, en que denuncia el comportamiento del señor J. con la señora M., dejando entrever que se estaría aprovechando de ella, controlando su patrimonio y sobremedicándola, entre otras cosas.

El escrito de acusación que remite el abogado del señor J. y la señora M. antes del juicio, a principios de enero de 2012, destila toda clase de juicios de valor y un odio poco disimulado hacia Aurora. Se dice en él:

"Nos hallamos ante una víctima totalmente desamparada, pues la Sra. M. es una anciana de más de 70 años de edad, con una enfermedad el Parkinson que le impide absolutamente la movilidad y la hace depender siempre de una persona que la cuide. La denunciada [...] aprovechándose de la confianza depositada por mi mandante [...] actuó con extrema vileza robando todo lo que pudo sin importarle en lo más mínimo el daño reiterado que estaba causando, y con absoluta frialdad procedió al robo del dinero, a la manipulación posterior de las libretas y al robo de las joyas al mismo tiempo que seguía tratando con mi patrocinada como si nada".

En el apartado sobre "circunstancias modificativas de la responsabilidad criminal", añade:

"La Sra. Aurora ha actuado con especial vileza contra una pobre mujer indefensa, anciana, impedida y enferma de Parkinson, aprovechándose de esas especiales circunstancias mientras trabajaba dentro de su casa 'cuidándola' [comillas suyas]; circunstancias que como es de ver debilitan la defensa de mi patrocinada y facilitan la impunidad de la delincuente. Sin olvidar que en todo momento la acusada ha obrado con abuso de la confianza depositada en ella, pues incluso tenía las llaves de la casa".

Pide un total de nueve años y nueve meses de prisión, más una multa e indemnización por valor de 51.900 euros. El fiscal, por su parte, señalará que 
Aurora habría ejecutado "un plan preconcebido", se habría aprovechado de su rol de cuidadora, y la acusará de un delito continuado de estafa o robo con fuerza, y de otro de hurto con el agravante del "abuso de confianza". Pedirá tres años de prisión por el primer delito, y 18 meses por el segundo, más una indemnización por valor de 25.650 euros.

Un año después, antes del juicio, la defensa solicitará al Juzgado que se autorice a Aurora a viajar a Argentina para visitar a una tía gravemente enferma. El fiscal se opondrá a la petición en un escrito muy breve. En cambio, el abogado de la acusación aprovechará para arremeter de nuevo contra Aurora, manifestando:

"Es evidente que tiene intención de fugarse y sustraerse de la acción de la justicia, puesto que ve la cercanía de la vista del juicio y por ende la sentencia que a todas luces será condenatoria con penas de prisión. Dicho sea con el máximo respeto, nos vemos en la obligación de desenmascarar el intento de la acusada de engañar al Tribunal con argumentos lacrimógenos [...] La acusada miente, miente sin ningún rubor, abusando de su derecho constitucional a mentir en su defensa, extendiéndolo de forma maliciosa para evadirse de la justicia y que no pueda ser condenada [...] ¿Pretende acaso engañarnos a todos? ¿Y no es mucha casualidad que precisamente esta supuesta tía que se está muriendo pida que sea precisamente la acusada quien acuda en sus últimos días? No es una cuestión de ser o no desalmado, cruel o duro, es una cuestión de tomadura de pelo que ni siquiera se sostiene con las propias afirmaciones de la acusada [...]. Esta parte, no sabe si es cierto que una familiar de la acusada se está muriendo, y qué más quisiera que poder demostrar la humanidad de la cual la acusada hizo gala de carecer al robarle a una pobre anciana. Más nos parece un urdido engaño, planificado, para sustraerse de la acción de la justicia. [...] No ofrece nada, solo pide, pide con mentiras, e intenta engañarnos a todos".

Celebrado el juicio en la Audiencia Provincial de Barcelona, la sentencia es dictada en febrero de 2015. Se condena a Aurora a dos años exactos y a una indemnización de 3300 euros por el delito continuado de estafa, con agravante de abuso de confianza; se le absuelve del de falsedad documental y hurto (el robo de las joyas no se considera probado). A pesar de entender que Aurora pudo cometer las sustracciones de las cuentas, siguiendo "un plan preconcebido" y aprovechándose de la facilidad de acceso a ellas, el juez arroja dudas sobre el testimonio y la actuación del señor J., sobre quien, dice, existen serias "sospechas".

La sentencia ahonda especialmente en el agravante del abuso de confianza, relacionándolo con el trabajo de cuidados y con la relación "especial" que siempre existiría entre empleadora y trabajadora, relación que generaría "una espe- 
cial confianza en virtud de la cual se inhibe la sospecha o la desconfianza [...] que permite una mayor facilidad para la comisión del delito". Tanto la acusación particular como el fiscal recurrirán la sentencia, aduciendo que la pena impuesta no se corresponde con el delito probado. El recurso será admitido por el Supremo, que subirá la pena de Aurora a dos años, cuatro meses y quince días. Posteriormente, Aurora pedirá la substitución de la pena de prisión por la de expulsión del país, a lo cual la acusación particular se opondrá, pidiendo además el ingreso inmediato en prisión. Un mes más tarde, Aurora solicita el indulto al Ministro de Justicia. Esgrimirá su reinserción y sobre todo el hecho de constituir "el soporte principal" en el cuidado de su marido - aquejado también de Parkinson -. Tres meses y medio después recibe la contestación, negativa. En diez días entra en prisión.

\section{Caso 2: el caso de Manuela}

Manuela nació en 1956. Es boliviana, nacionalizada española desde 2011. Llegó a España hace más de 10 años, y desde su llegada ha trabajado en el sector del hogar y los cuidados, en residencias geriátricas y en domicilios particulares.

En mayo de 2014 Manuela empieza a trabajar como empleada doméstica para una familia acomodada, cuidando una señora de 97 años que vive entre Barcelona (zona alta) y Tarragona, donde la familia tiene la segunda residencia. En la casa trabajan otras cuatro personas: la trabajadora del hogar de fines de semana y nocturnidad, la "canguro" de los niños, el chofer y el jardinero. En mayo de 2015, un año después de ser contratada, Manuela decide irse, firmando una baja voluntaria, debido al estrés y las dolencias que le acarrea trabajar ahí.

Formalmente y según contrato, Manuela trabaja en régimen de externa de lunes a viernes, aunque pernocta en el domicilio de domingo a jueves. El contrato estipula 40 horas semanales y un salario de 1035 euros, pero realmente realiza un total de 77 horas semanales, 37 horas más de las que dice el contrato. Había acordado (verbalmente) que le pagarían 1200 euros, más Seguridad Social y pagas extras. No le pagan lo convenido. Manuela reclama en diversas ocasiones y advierte con acudir a Inspección de Trabajo. Finalmente, la familia accede y a partir de enero 2015 y durante los meses sucesivos el hijo de la señora (el señor A.), empresario y abogado, empieza a realizar ingresos en la cuenta bancaria de Manuela en concepto de cantidades debidas (pagas extras, vacaciones y otras cantidades); según la abogada de Manuela, "para que calle".

Cuando a finales de mayo de 2015 Manuela presenta la baja voluntaria, todavía le deben dinero y no le han pagado el mes de mayo. Manuela llama a la nuera de la señora y le comunica que deja el trabajo alegando agotamiento físico. El hijo la cita en su bufete de abogados y le hace firmar el documento de baja voluntaria, redactado por él. 
A los pocos días, vuelve a citar a Manuela y le comunica que le debe retornar un dinero que ha sido ingresado en su cuenta por error. Poco después, Manuela recibe un burofax en que le reclaman formalmente que "en el plazo de dos días restituya la suma de 5015 euros que le fue ingresada indebidamente en su cuenta en concepto de nóminas" y le advierten de futuras acciones judiciales en caso de no atender la petición. Manuela se niega a pagar tal cantidad y de nuevo reclama lo que le deben bajo advertencia de acudir a Inspección de Trabajo.

"Le dije que no. Que era él quien me debía dinero. Se puso agresivo. Lo único que recuerdo es que le gritaba a su secretaria: iCharo, despide a esta mujer! Me dijo que, si no pagaba en el plazo, que me atendiera a las consecuencias. Yo le dije: 'Si entre usted y yo no nos podemos entender, iré a Inspección de Trabajo'. Y ya fue cuando él me denunció a los Mossos” [Manuela, entrevista, julio 2018].

Acto después, la familia empleadora interpone una denuncia penal por estafa contra Manuela en que se afirma que ha engañado y estafado a la familia. Supuestamente habría engañado a la señora para que convenciese a su hijo de que le ingresara nóminas ya ingresadas, al parecer sin que él se hubiera percatado de tal duplicidad. Manuela recibe una llamada de los Mossos.

"Los Mossos me amenazaron: 'ya sabes porque te llamamos...' Y ahí empezó el calvario. No dormía. Fui donde el médico de cabecera y me dijo: 'tienes que coger un abogado'. En 60 años jamás me había pasado esto que me llamara la policía. Yo no tengo antecedentes, mi familia es íntegra, está libre de denuncias. iMe afectó tanto! '¿Qué voy a hacer, dónde voy a ir?' Fui a Inspección de Trabajo y me dijeron que ya no podían hacer nada porque yo ya había firmado la renuncia; y entonces me dieron una boleta para ir a buscar un abogado de oficio. Hice todo un peregrinaje, y tuve la gran suerte de encontrarlas a ellas [las abogadas que han llevado su caso]" [Manuela, entrevista, julio 2018].

Asesorada por su abogada, Manuela interpone demanda de reclamación de cantidad contra su empleadora (agosto de 2015). La cantidad reclamada es de 10.329 euros.

En su declaración como imputada frente al Juzgado de Instrucción (diciembre de 2015), Manuela declara que tales pagos se correspondían con los pagos atrasados, que no había habido pagos duplicados. Y que, frente a sus reclamos de incumplimiento de horarios y pagos, la señora le habría dicho que "los papeles son papeles", y que "ya lo arreglarían, lo hablarían con su hijo". Que le darían la diferencia en mano y que "no se lo dijera a nadie". Ella no aceptará y exigirá al hijo que le ingrese el dinero en su cuenta bancaria. Que a la otra 
cuidadora [empleada los fines de semana y nocturnidades], de los 2115 euros que ganaba, 1500 euros se lo daban "en negro" y el resto se lo ingresaban en cuenta, y querían hacer lo mismo con ella, a lo que ella se negó.

La respuesta que Manuela obtiene por parte de la empleadora cuando reclama lo pactado expresa el alto grado de normalización del fraude y la vulneración de derechos laborales que caracteriza este sector (el contrato no refleja las horas reales trabajadas; se le ofrece abiertamente el pago "en negro" de la cantidad extra que le corresponde por el número real de horas trabajadas; le descuentan del sueldo la cuota a la Seguridad Social; se asume que duerme en el domicilio sin estar contratada en régimen de interna...).

Manuela insiste en que hacía jornadas interminables, que no sólo cuidaba la señora - la cual requería una atención continuada y permanente -, sino que limpiaba la casa, cocinaba para toda la familia (12 personas) y también para el personal que trabajaba allí; planchaba, atendía invitados los días festivos, cuidaba los nietos de la señora... Afirma que no tenía un momento de descanso, que no salía de la casa excepto para ir a comprar, que durante la noche también trabajaba, puesto que la empleada contratada para la noche no podía mover sola a la señora. Que cuando se sentaba a descansar un momento, la señora la ponía a abrillantar plata si hacía falta, alegando que "no le pagaba para estar sentada".

"Ella decía que las internas tendríamos que estar agradecidas por tener todo eso, techo, comida y ropa. Me llamaba Catalina, porque no se acostumbraba a decirme por mi nombre. Me decía: 'Mi Catalina, hasta que me muera te tienes que quedar; hasta que cierre los ojos no me vas a dejar'. Yo le decía: 'No creo señora, porque su hijo no me está pagando lo pactado'. 'Ya te daré yo, no te preocupes', me decía. Pero yo no quería recibirle el dinero a ella" [Manuela, entrevista, julio 2018].

Contraviniendo la declaración de Manuela, el demandante (hijo de la señora) alega en su declaración (febrero de 2016):

"Que la denunciada nunca había realizado una jornada laboral superior a 8 horas, de modo que cuando en la denuncia se afirma que había realizado unas horas extras, éstas se refieren a días festivos que eran pagados a razón de $50 €$ diarios. Que a su madre le desaparecieron $3000 €$ del armario [algo que nunca se denunció] y que, cuando se dio cuenta de que había cobrado por duplicado las nóminas y que se había quedado con el dinero correspondiente, le preguntó si sabía algo de esta cuestión, a lo que Manuela le contestó que no tenía ninguna prueba. Que al quedar extinguida la relación laboral, la denunciada firmó un recibo de saldo y finiquito dándose por saldada y finiquitada por todos los conceptos y comprometiéndose a nada más pedir o reclamar. Que jamás se le hizo ningún pago en negro, ni se le 
propuso pagarle de tal forma, y que las nóminas las recibía a través de transferencia bancaria".

A las preguntas de la abogada de Manuela, el demandante manifestará:

"Que Manuela no tenía trabajo suficiente para cubrir las 8 horas, y muchos días ni siquiera trabajaba la jornada completa. Que su madre no precisaba una atención continuada, pues es relativamente autosuficiente. Que Manuela no atendía a más personas fijas en la casa. Que de 15'30 a 18 '30 h, Manuela a veces, en Tarragona, solía ir a la playa. Que el declarante ayuda a su madre en temas económicos, pero no tiene un control riguroso de sus cuentas. Que cobra una pensión, en la misma cuenta en la que se pagaba la nómina de Manuela. [...] Que no es cierto que desde el inicio de la relación laboral Manuela se quejara de que el sueldo fuera inferior al pactado con la madre. Que Manuela cobró todos los meses. [...] Que durante la relación laboral había buena relación con Manuela puesto que su madre tenía toda la confianza depositada en ella. Que en ningún momento Manuela le dijo que iba a ir a Inspección de Trabajo”.

En 2017 se celebra el juicio en la Audiencia provincial de Barcelona, por considerarse un delito grave. Le piden tres años de prisión y devolver 5015 euros (la abogada nunca se lo dijo a Manuela, temiendo que no soportara la presión). Cabe añadir que, previamente, la parte demandante no había acudido al acto de conciliación celebrado en enero, alegando que "la citación llegó al buzón de la madre a su casa de Barcelona, cuando ella se encontraba en Tarragona".

Durante el juicio, el demandante se muestra nervioso y muy agresivo. Manuela se derrumba. Su abogada relata cómo se sucede el juicio:

"Al principio ella [la trabajadora] es completamente cuestionada. Pero a medida que avanza el juicio, veo como al juez le va cambiando la cara. Entra con un prejuicio: 'otra sudamericana que le ha robado a la empleadora'. Pero algo cambia. Sobre todo, cuando declara él. Yo creo que el juez no se creyó nuestra versión, pero sí que vio que él no era responsable. Frente a una acusación de estafa existe el deber de diligencia, de vigilar que no te timen. El juez ve una irresponsabilidad. Cuando se le pregunta sobre la supuesta estafa, su testimonio no se aguanta:

- Usted es abogado, es empresario.

- Sí, tengo muchas empresas...

- ¿Y usted no se enteró que había ingresos duplicados?

- No. Me llamaron de la entidad bancaria para decirme que estaba en número rojos. 
- ¿Usted estaba en números rojos por 1000 euros? ¿Usted no usa el servicio de banca electrónica, y no mira los ingresos?

- Bueno, a veces...

- ¿Y usted está diciendo que una persona sin estudios primarios ha estafado a un empresario solvente como usted...?"

El juicio culmina con una absolución. Según la abogada, la acusación de estafa - y no de robo - habría favorecido tal resolución, puesto que es más difícil de demostrar. También el hecho de tener una demanda laboral en curso interpuesta por la demandada. Tras la absolución, se celebra el juicio laboral, que culmina con un acuerdo de 2000 euros. Según la abogada de Manuela, se trata de un caso de obstinación, odio de clase y venganza:

"Cuando entras en la Audiencia ves cómo es un sistema judicial injusto; cómo van las clases sociales, cómo unas chafan a las otras... Se trata de una señora boliviana, que no se lo ha dicho ni siquiera a su hija, contra un empresario del Opus Dei con el poder que esto conlleva, con un abogado de pago, con el fiscal a favor suyo, porque la fiscalía apretó... Si no llegamos a interponer la denuncia laboral, hubiéramos perdido. [...] La denuncia se entiende desde el odio de clase y desde el poder. Ellos tienen el poder sobre ella. Ella es una persona con un nivel sociocultural bajo, con tres hijos, muy pobre y muy precaria, pero tiene un mínimo sentido del honor. Ella sólo reclama lo que cree que merece. '¿Cómo te atreves a hacerme esto?' Es odio, es escarnio. El otro abogado le advirtió que no iba a ningún lado, pero él se obstinó. Es él [el hijo de la señora] que lo mueve todo... Con la señora se habían generado relaciones de mucha confianza. Cuando pasó todo esto, Manuela lloraba por la señora. [...] Aquí no hay estrategia jurídica. Aquí hay vísceras. Hay impunidad".

A pesar de serle favorable, Manuela recuerda el proceso como "la peor experiencia de su vida". Dice no recordar nada del juicio, ni siquiera qué es lo que ella declaró. Se enfermó, cayó en una depresión profunda. Acabado el juicio, se fue a Bolivia por un año a recuperarse. Estuvo en tratamiento con una psicóloga y luego regresó. Después de esta experiencia, tomó la decisión de no volver a trabajar en un domicilio:

"Hay trabajos en domicilios, pero no quiero saber nada. Me gusta atender gente mayor, pero no quiero ir a cuidar a nadie. A un domicilio no quiero entrar nunca más, prefiero estar de fregaplatos, lavabos, lo que sea. $\mathrm{Ni} \mathrm{a}$ limpiar quiero ir. He quedado con este trauma. Es algo inhumano lo que me han hecho" [Manuela, entrevista, julio 2018]. 


\section{ACUSACIONES FRAUDULENTAS, MERECIMIENTO \\ E INSTRUMENTALIZACIÓN DEL DERECHO Y LA JUSTICIA}

Aunque estos dos casos presentan diferencias entre sí, en ambos observamos una clara instrumentalización de la justicia y el derecho penal: la utilización de éste (por parte de los/as empleadores/as) como arma para conseguir o mantener una posición de ventaja en un conflicto de índole personal/laboral. Que dicha instrumentalización sea posible y efectiva depende, por lo demás, de la existencia de toda una serie de prejuicios y estereotipos alrededor de las mujeres inmigrantes trabajadoras del hogar, que impregnan también el sistema judicial. En el caso de Manuela, la acusación de estafa se usa como recurso para desacreditar y contrarrestar el reclamo de derechos de la trabajadora; en el de Aurora - aunque de fondo puede existir el reclamo de derechos laborales (el forzar el disfrute de las vacaciones) - parece ser una extorsión directa o abuso de la posición vulnerable de la trabajadora.

El caso de Aurora es un caso extremo que evidencia la exposición frecuente a riesgos graves que sufren las trabajadoras, riesgos que tienen que ver con el propio oficio - el trabajo en el domicilio del / de la empleador/a, el tipo de relación personal que abre la puerta a la acusación de abuso de confianza, la naturaleza ambigua de la relación laboral, etc. -; y con los prejuicios señalados alrededor de las mujeres trabajadoras, migrantes y pobres, especialmente con el estereotipo de la "mujer sudamericana que roba a la anciana desvalida". Todo ello hace patente una gran indefensión y también el "ensañamiento" por parte de los actores en situación de ventaja (empleadores/as, abogado de la acusación, fiscal y policía).

El caso de Manuela resulta ilustrativo además de los riesgos a los que las trabajadoras se exponen si reclaman derechos, mostrando, de nuevo, su extrema vulnerabilidad e indefensión frente al empleador, quien no solo se mueve por una motivación económica, sino que busca el castigo y la represalia moral frente a lo que considera un acto de insubordinación. La trabajadora que osa insinuar que acudirá a Inspección de Trabajo para denunciar una irregularidad, no sólo se arriesga a perder su trabajo (en muchos casos, el reclamo de derechos o el mero asesoramiento sindical conlleva el despido, disfrazado de desistimiento), sino a sufrir represalias de carácter judicial. La reclamación de derechos no se tolera, y produce una reacción adversa, generalmente desmesurada, por parte del / de la empleador/a. De nuevo se observa el "ensañamiento" propio de una relación estructural de abuso de poder, en respuesta a una trabajadora que ha osado reclamar algo que no le corresponde, de lo que no es "merecedora" - el salario pactado informalmente entre las partes - y que ha tenido el atrevimiento de interponer - tras ser denunciada - una demanda laboral.

Sostenemos que dicho ensañamiento es una respuesta frente a lo que el/la empleador/a considera el quebrantamiento de un orden moral y de estatus. Por un lado, hay un uso instrumental del derecho y la denuncia penal: mediante 
la denuncia por hurto agravado, robo o estafa, el/la empleador/a descentra el conflicto del plano meramente laboral, en el que estaría en falta por incumplir sus obligaciones legales, y contraataca, siendo la denuncia penal un arma en la negociación laboral. Pero, por otro lado, este ataque es desproporcionado y debe entenderse más allá del cálculo y el uso estratégico del derecho; se relaciona con la naturaleza personal, el tipo de vínculo y moralidad que envuelve el trabajo del hogar y los cuidados.

La falta de proporcionalidad cobraría sentido sólo en la esfera de las relaciones personales y la moralidad, donde a ojos del / de la empleador/a ciertas obligaciones y lealtades han sido traicionadas. El/la empleador/a se siente agraviado/a por el comportamiento desleal de una trabajadora a quien "ha ayudado" en un momento de necesidad (el/la empleador/a pasa a ser acreedor de supuesta gratitud) y que ha osado después quebrar con sus reclamos una relación basada en la confianza, la reciprocidad y el afecto establecidos en el orden privado (Pérez y Canevaro 2016: 181). Una trabajadora a la que se le ha ofrecido, no solo trabajo, sino abrigo y cobijo, y que ha podido incluso llegar a ser considerada - dentro de lo que diversas autoras han llamado "ambigüedad afectiva" - "parte de la familia" (Graham (1995 [1988]; Goldstein 2003; Brites 2007; Gorban 2012). Una trabajadora que ha vulnerado con su comportamiento los "repertorios de demarcación" (Gorban 2012: 40) que prescriben lo que significa ser una "buena empleada" - callada, discreta, sumisa, agradecida, invisible. Límites, por cierto, que exigen ser confirmados y dramatizados de forma cotidiana y que simbolizan muy bien la tensión entre lo laboral y lo servil, entre la distancia social y la proximidad física y afectiva.

Por otro lado, la literatura etnográfica ha descrito también como las relaciones entre trabajadoras y empleadores/as tienen a menudo un final abrupto, en forma de reacción airada por parte del/de la empleador/a; fruto de la naturaleza borrosa de unas relaciones que se sitúan justamente a medio camino entre lo personal y lo profesional, y en las cuales el/la empleador/a demanda a la trabajadora una dedicación exclusiva a su familia, lealtad y gratitud continuas, y donde los reclamos (de derechos laborales, de un mínimo "espacio vital", etc.) se entienden como agravios y deslealtades (Hondagneu-Sotelo 2004; Pérez y Canevaro 2016: 181).

Siguiendo la propuesta de Luís R. Cardoso de Oliveira (2004: 26) en torno a los conceptos de reconocimiento, honor, dignidad y reciprocidad en la resolución de disputas, podemos igualmente interpretar la reacción del empleador de Manuela como una respuesta motivada por la indignación a lo que percibe como una falta de reconocimiento. En la línea de lo que el propio Cardoso de Oliveira señala, es relevante hacer notar aquí la expectativa de reparación, cuyo sentido excede lo material (la voluntad de ser compensado económicamente) y se adentra en lo personal, en vistas a restituir una identidad social quebrantada. Así, la demanda interpuesta en contra de la trabajadora buscaría "dar visibilidad 
al insulto o acto de desconsideración - derivado de la falta de reconocimiento como una agresión objetiva, merecedora de reparación" (Oliveira 2004: 26).

Salvando las distancias, el contexto recuerda al de algunos sistemas sociales marcados por la jerarquía extrema y la desigualdad, en el que se rechazan situaciones como la indefinición de estatus o el trato impersonal y, por lo tanto, potencialmente igualitario. Las acciones de los subordinados que no respetan la jerarquía personal son vistas como ofensivas, como desafíos. Y una serie de actos simbólicos (en el fondo, de fuerza) sirven para recordar y volver a imponer de manera violenta dichas jerarquías (DaMatta 1997). ${ }^{8}$ En nuestro caso, las demandas de las trabajadoras son percibidas por los/as empleadores/as como una acción que ofende y desafía el orden jerárquico, y sorprendentemente - para quien desde una óptica positivista conciba derecho y moral como ámbitos separados - se recurre a la ley para punir dicha ofensa y reforzar las jerarquías, evocando, por cierto, una connivencia implícita con la institucionalidad vigente.

\section{A MODO DE CONCLUSIÓN}

A la luz de los casos expuestos, vemos como el lenguaje del merecimiento se muestra muy pertinente para iluminar sentidos de justicia, y mostrar los encabalgamientos entre derecho y moral. La demanda penal (sus testimonios, el tono de los escritos...) y la pena exigida - a todas luces desmedida - están impregnadas de una moralidad que excede lo legal. Analizados los procedimientos judiciales, se observa, en este sentido, como las prácticas de los operadores jurídicos no pueden explicarse como una mera aplicación del derecho positivo, sino que aparecen fundamentadas en categorías morales, discriminando así entre colectivos y, en consecuencia, produciendo y reproduciendo formas de categorización, opresión, dominación e inferiorización.

Se reproduce así el orden de subordinación sobre el que se asienta, en la práctica y más allá del régimen contractual, la relación laboral del trabajo del hogar. La ley (reglamentación laboral vigente) - de por sí deficitaria en materia de reconocimiento de derechos, pero que aspira a situar la relación laboral en un marco contractual formalizado - no logra interpelar las categorías e ideas corrientes sobre quién es y quién no es merecedor de ser reconocido como trabajador/a con derechos (Segato 2003). Dentro de un imaginario de subordinación de género, clase y raza, compartido entre empleadores/as, abogados y operadores jurídicos, recurrir al estereotipo de la "trabajadora inmigrante que roba" (vs. la anciana autóctona, honrada y desvalida) contribuye a reforzar las

8 Una idea similar emerge en el trabajo de M.C. Coelho (2006: 65-79), cuando desde la perspectiva teórica del contextualismo describe las reglas que rigen el intercambio de regalos entre las trabajadoras del hogar y sus patronas en Brasil, como un modo de dramatizar las estructuras jerárquicas y de poder dentro de las cuales se dirime la relación laboral. 
sospechas previas que se tienen respecto a las cualidades morales y éticas de las trabajadoras. Se reafirma así un régimen de cuidado sostenido sobre el despojo material y simbólico persistente de las trabajadoras inmigrantes.

Todo ello produce en las trabajadoras, a su vez, un sentimiento profundo de injusticia y agravio. La acusación de robo o estafa supone una afrenta moral - además de un problema económico y material, psicológico, administrativo (puede afectar la renovación de la residencia legal), etc. -, sintiéndose no merecedoras del trato injusto recibido. Contestarán con apelaciones a su honestidad, reputación e integridad morales, y a su "buen servicio" y desempeño profesional. Contestaciones, no obstante, en las que también se invoca la ley y el efectivo cumplimiento de sus derechos, cuyo conocimiento se refuerza en ocasiones fruto del propio procedimiento y del trabajo con abogadas como las que colaboraron en esta investigación. Así, el papel del derecho oficializado es ambiguo y complejo, teórica fuente de garantías y derechos, pero aquí mostrándose básicamente como fuente de subordinación.

\section{BIBLIOGRAFÍA}

Almena COOPERATIVA FeministA, 2019, Tras la Puerta: Cómo Informan los Medios sobre el Trabajo del Hogar y los Cuidados, disponible en < https://almenafeminista.org/wp-content/ uploads/2019/05/informe-tras-la-puerta.pdf > (última consulta en febrero de 2020).

ATENCIO, Graciela, et al., 2016, Feminicidio en Euskadi y Navarra 2010-2015: Casos, Tratamiento en Prensa y Análisis de Sentencias. Bilbao, Mugarik Gabe, disponible en < https:/feminic idio.net/sites/default/files/informe_feminicidio_euskadi_navarra_2010_2015.pdf > (última consulta en febrero de 2020).

BOFILL-POCH, Sílvia, 2017, “'Otro trabajo del hogar es posible’: procesos de lucha por el reconocimiento y dignificación de los cuidados en tiempos de crisis", Quaderns-e de l'ICA, 22 (2): 133-149.

BOFILl-POCH, Sílvia, y Norma VÉLIZ, 2019, Una Violència Oculta: Assetjament Sexual en Dones Migrades Treballadores de la Llar i les Cures. Barcelona, Fundació Josep Irla.

BORRell, Mònica, 2015, El Servei Domèstic a la Ciutat de Barcelona, 1900-1950. Barcelona, Universitat de Barcelona, tesis doctoral.

BRITES, Jurema, 2007, "Afeto e desigualdade: gênero, geração e classe entre empregadas domésticas e seus empregadores”, Cadernos Pagu, 29: 91-109.

CANEVARO, Santiago, 2015, "Juicios, acusaciones y traiciones: moralidades en disputa en el servicio doméstico en Buenos Aires”, Século XXI: Revista de Ciências Sociais, 5 (1): 26-52.

CANYELlES, Caterina, 2019, Masclisme i Cultura Jurídica: Una Etnografia del Procés Judicial de la Violència de Gènere. Barcelona, Universitat de Barcelona, tesis doctoral.

CMIB - Consell Municipal d'Immigració de Barcelona, 2017, "Propostes per a la dignificació del treball de la llar i la cura de les persones”, Ajuntament de Barcelona, disponible 
en < https://ajuntament.barcelona.cat/consell-municipal-immigracio/sites/default/files/d ocuments/doc.gt_llar_.00.ca_.pdf > (última consulta en febrero de 2020).

COELHO, Maria Claudia Pereira, 2006, O Valor das Intenções: Dádiva, Emoção e Identidade. Rio de Janeiro, Editora FGV.

DaMATTA, Roberto, 1997, "Sabe com quem está falando? Um ensaio sobre a distinção entre indivíduo e pessoa no Brasil”, en Roberto DaMatta, Carnavais, Malandros e Heróis: Para Uma Sociologia do Dilema Brasileiro. Rio de Janeiro, Rocco, 179-248.

EILBAUM, Lucía, 2011, "Familia, justicia y moralidades en el conurbano bonaerense", Revista Anthropológicas, 22 (1): 7-35.

GOLDSTEIN, Donna, 2003, "The aesthtics of domination: class, culture, and the lives of domestic workers", in D. Goldstein, Laughter Out of Place: Race, Class and Sexuality in a Rio Shantytown. Berkeley, University of California Press, 58-101.

GORBAN, Débora, 2012, "Empleadas y empleadoras, tensiones de una relación atravesada por la ambigüedad”, Revista Española de Investigaciones Sociológicas (REIS), 140 (1): 29-48.

GRAHAM, Sandra L., 1995 [1988], House and Street: The Domestic World of Servants and Masters in Nineteenth-Century Rio. Austin, University of Texas Press.

HONDAGNEU-SOTELO, Pierrette, 2004, "Blowups and other unhappy endings", en Barbara Ehrenreich y A. R. Hochschild (coords.), Global Woman: Nannies, Maids, and Sex Workers in the New Economy. Nueva York, First Owl, 55-69.

MACAYA, Laura, 2013, Esposas Nefastas y Otras Aberraciones: El Dispositivo Jurídico como Red de Construcción de Feminidad. Barcelona, Diletantes.

MACKENZIE, Catriona, 2014, "The importance of relational autonomy and capabilities for an ethics of vulnerability", en C. Mackenzie, W. Rogers y S. Dodds (coords.), Vulnerability: New Essays in Ethics and Feminist Philosophy. Nueva York, Oxford University Press, 33-59.

MARTÍNEZ-BUJÁN, Raquel, 2011 , "La reorganización de los cuidados familiares en un contexto de migración internacional”, Cuadernos de Relaciones Laborales, 29 (1): 93-123.

NOGUEIRA, Julia, y Joseba ZALAKAIN, 2015, La Discriminación Múltiple de las Mujeres Inmigrantes Trabajadoras en Servicios Domésticos y de Cuidado en la Comunidad Autónoma de Euskadi. Vitoria, Emakunde - Instituto de la Mujer.

OFFENHENDEN, María, 2017, "Si Hay que Romperse Una, Se Rompe": El Trabajo del Hogar y la Reproducción Social Estratificada. Tarragona, Universitat Rovira i Virgili, tesis doctoral.

OLIVEIRA, Luís R. Cardoso de, 2004, "Honor, dignidad y reciprocidad", Cuadernos de Antropología Social, 20: 25-39.

PÉREZ, Inés, y Santiago CANEVARO, 2016, "Entre lo público y lo privado: empleadores y trabajadoras domésticas frente al Tribunal del Trabajo Doméstico de la ciudad de Buenos Aires", Política y Sociedad, 53 (1): 169-186.

SEGATO, Rita, 2003, Las Estructuras Elementales de la Violencia. Buenos Aires, Universidad Nacional de Quilmes.

TERRADAS, Ignasi, et al., 2016, La Violencia contra las Mujeres en el Contexto Social y Económico Actual: Un Estudio Antropológico de los "Condicionantes Socioculturales" en la Praxis Judicial. Madrid, Instituto de la Mujer. 